\title{
Low algal diversity systems are a promising method for biodiesel production in wastewater fed open reactors
}

\author{
Meenakshi Bhattacharjee ${ }^{1}$ and Evan Siemann ${ }^{1, *}$ \\ ${ }^{1}$ Department of Biosciences, Rice University, 6100 Main St., Houston, TX 77005, USA
}

Planktivorous fish which limit zooplankton grazing have been predicted to increase algal biodiesel production in wastewater fed open reactors. In addition, tanks with higher algal diversity have been predicted to be more stable, more productive, and to more fully remove nutrients from wastewater. To test these predictions, we conducted a 14-week experiment in Houston, TX using twelve 2,270-L open tanks continuously supplied with wastewater. Tanks received algal composition (monocultures or diverse assemblage) and trophic (fish or no fish) treatments in a full-factorial design. Monocultures produced more algal and fatty acid methyl ester (FAME) mass than diverse tanks. More than $80 \%$ of lipids were converted to FAME indicating potentially high production for conversion to biodiesel (up to $0.9 \mathrm{~T} \mathrm{ha}^{-1} \mathrm{y}^{-1}$ ). Prolific algal growth lowered temperature and levels of total dissolved solids in the tanks and increased $\mathrm{pH}$ and dissolved oxygen compared to supply water. Algae in the tanks removed $91 \%$ of nitrate- $\mathrm{N}$ and $53 \%$ of phosphorus from wastewater. Monocultures were not invaded by other algal species. Fish did not affect any variables. Our results indicated that algae can be grown in open tank bioreactors using wastewater as a nutrient source. The stable productivity of monocultures suggests that this may be a viable production method to procure algal biomass for biodiesel production.

Key Words: biofuel; fatty acid methyl ester; monoculture; open reactor; wastewater

\section{INTRODUCTION}

Global warming is receiving a great deal of attention, while on the other hand rising global energy demand combined with increasingly uncertain geopolitical conditions are making the production of energy from existing non-renewable sources more difficult, costly and unpredictable (Rizzi et al. 2014). Algae offer a tangible promise to fulfill the need for an alternative source of energy. While growing algae outdoors is generally expensive, the cost of this method of cultivation can be greatly reduced by using wastewater as a medium for their growth (Ahrens and Sander 2010, Clarens et al. 2010, Smith et al. 2010, Park et al. 2011, Stockenreiter et al. 2012). Algae can also produce a variety of high value compounds such as biodiesel and biofertilizer, without contributing to atmospheric carbon dioxide (Borowitzka 1995, Olaizola 2003, Banerjee and John 2005, Banerjee and Kushwaha 2005).

Wastewaters have been underutilized for their nutrient value resulting in downstream ecological disruption (Walsh et al. 2005). As a general practice, wastewaters are treated chemically and physically to remove undesired substances. Use of chemicals in treating wastewaters has serious long-term environmental effects and is expensive (Walsh et al. 2005). Therefore, there is a need to have a treatment method that has low environmental impacts and is economical. One simple solution would be the use of algae for wastewater treatment which can overcome
(1) $\$$ This is an Open Access article distributed under the terms of the Creative Commons Attribution Non-Commercial License (http://creativecommons.org/licenses/by-nc/3.0/) which permits unrestricted non-commercial use, distribution, and reproduction in any medium, provided the original work is properly cited.
Received January 18, 2015, Accepted March 6, 2015

* Corresponding Author

E-mail: siemann@rice.edu

Tel: +1-713-348-5954, Fax: +1-713-348-5232 
most of the limitations of chemical treatment and provide cost effective removal of nutrients mainly nitrogen $(\mathrm{N})$ and phosphorus $(\mathrm{P})$ from the water in a process that would create fuels while reducing high nutrient loads in downstream watersheds (Banerjee and Yadav 2009, Park et al. 2011, Pittman et al. 2011, Rawat et al. 2011). Many microalgae have been screened with potential for biodiesel production and nutrient removal from treated municipal sewage (Chisti and Yan 2011, Odlare et al. 2011, Fortier and Sturm 2012).

Bioenergy production from algae is promising because productivity is high per land area, producing almost 300 times more oil per acre than conventional crops (Laws et al. 1988, Craggs et al. 2011, Dalrymple et al. 2013). Also algal cultivation does not compete with food production, algae have very fast growth rates which permit several harvests within a short time frame, and algae production absorbs $\mathrm{CO}_{2}$ from the atmosphere. Lipid and carbohydrate rich algae are a superior feedstock compared to many biofuel crops, especially for biodiesel production (Lam and Lee 2012). Many algal studies and energy evaluations have provided varying results (Huntley and Redalje 2007, Bruton et al. 2009, Batan et al. 2010, Brennan and Owende 2010, Clarens et al. 2010, Chisti and Yan 2011, Sturm and Lamer 2011, Lam and Lee 2012, Ramachandra et al. 2013).

However, life cycle analyses (LCA's) that consider all energy inputs to algae production indicate that fertilizer inputs may contribute to poor energy gain in algae cultivation including biodiesel production from microalgae produced in outdoor ponds (Lardon et al. 2009, Batan et al. 2010, Clarens et al. 2010, Smith et al. 2010, Stephenson et al. 2010, Park et al. 2011). Most of these studies have assumed that the algal ponds will be supplied with chemical fertilizers in order to meet the $\mathrm{N}$ and $\mathrm{P}$ requirements for algal growth (Smith et al. 2010, Park et al. 2011). It was found that algal biodiesel could actually generate greenhouse gas emissions and require significantly more energy inputs compared to conventional crops (Smith et al. 2010, Park et al. 2011). At the same time it has also been proposed that most of the environmental burden associated with algae could be removed if wastewater was used as a nutrient source (Smith et al. 2010, Park et al. 2011). Most LCA's use lab scale data for productivity and lipid content to design virtual biofuel production facilities because limited information is available on algal productivities and $\mathrm{N}$ and $\mathrm{P}$ removal rates achieved in wastewater fed outdoor systems (Smith et al. 2010, Sturm et al. 2012). Use of treated wastewater as a fertilizer source for algal growth eliminates the energy used in producing chemi- cal fertilizers while simultaneously reducing eutrophication through removal of nutrients (mainly $\mathrm{N}$ and $\mathrm{P}$ ) from wastewater (Clarens et al. 2010, Smith et al. 2010).

Cultivating algae in open reactors that may be colonized by other algae and by herbivorous invertebrates presents challenges in terms of stability of production (Smith et al. 2010). It has been suggested that diverse algal assemblages may contribute to more productive and / or more stable open reactors because of a generally positive relationship among plant diversity, stability, and productivity (McCann 2000, Smith et al. 2010, Rooney and McCann 2012, Stockenreiter et al. 2012) but tests of this are lacking in algal production systems. In a small scale test (reaction wells), Stockenreiter et al. (2012) found that more diverse algal assemblages had higher lipid production. Because an abundance of planktivorous fish is often associated with suppression of herbivorous zooplankton (that naturally colonize outdoor tanks) and high standing crops of algae (Carpenter et al. 1985, 1995), it has been suggested that including planktivorous fish increases algal production (Smith et al. 2010, Sturm et al. 2012). In the single test of this principle, Sturm et al. (2012) found increased production when fish were present in wastewater fed open tanks stocked with algal assemblages collected from local ponds.

In the present study, open tank systems were used for algal biofuel production which integrates wastewater treatment and algal biomass production to test whether 1) diverse assemblages of algae are more resistant to invasion and have greater, more stable productivity (mass, lipids, fatty acid methyl ester [FAME]) than low diversity algal assemblages, 2) inclusion of planktivorous fish increases stability and productivity of these open tank systems, and 3) greater algal diversity and / or the presence of planktivorous fish increase the removal of nutrients (N \& P) from wastewater.

\section{MATERIALS AND METHODS}

\section{Location and tank set-up}

Outdoor experiments were conducted at a City of Houston wastewater treatment plant at Bellaire Boulevard and 8 Loop West $\left(29.70821^{\circ} \mathrm{N}, 95.56657^{\circ} \mathrm{W}\right)$ that ran from July to November. We used treated wastewater (post-clarifier) as the nutrient source for open tank bioreactors. There were twelve, 2,270-L (2.43 m diameter, 61 cm deep) open-top plastic tanks that were operated as continuous-flow reactors (seven day hydraulic residence 
time). Water was drawn from the top meter of the clarifier, passed through a $400-\mu \mathrm{m}$ polyester filter, and put into the tanks. To maintain even mixing the tanks were continuously aerated using a fine bubbler diffuser $\left(\sim 10 \mathrm{~L} \mathrm{~min}^{-1}\right)$. Each tank overflowed through a stand pipe into a collection system.

These bioreactors were used to grow different lipid rich algae and natural algal phytoplankton samples that could be processed to make biodiesel or biocrude. We ran experiments using three algal taxa (Spirulina platensis UTEX LB 1926 [blue-green algae or Cyanobacteria], Chlorella sp. UTEX 2248 [green algae or Chlorophyta], and Scenesdesmus obliques UTEX 393 [green algae or Chlorophyta]) that were obtained from the Culture Collection of Algae at University of Texas, Austin. All three algal taxa were cultured in the media recommended for their growth by the culture collection, maintained in culture media also obtained from this source, and pre-cultured before use so that exponentially growing algae could be used for seeding the experiments. Spirulina was grown in Zarrouk's medium and Chlorella and Scenedesmus were grown in Bold $3 \mathrm{~N}$ medium. To compare natural algal communities with laboratory grown monocultures, we acquired phytoplankton samples from two rivers and a lake in Houston (Buffalo Bayou [29.76117 N, 95.38832 W], Brays Bayou [29.69766 ${ }^{\circ} \mathrm{N}, 95.41008^{\circ} \mathrm{W}$ ], McGovern Lake $\left.\left[29.71754^{\circ} \mathrm{N}, 95.39087^{\circ} \mathrm{W}\right]\right)$ by dragging a plankton net through approximately $600 \mathrm{~L}$ of water at each location. Samples were filtered through $100-\mu \mathrm{m}$ mesh to remove meso-zooplankton and stored in a common cooling box carrying the cultured algae during transportation to the wastewater facility. These mixed cultures were not grown together in the laboratory before use but directly seeded in the tanks. At the beginning of the experiment and at regular intervals during the experiment, species composition of algal assemblages in each tank was determined by microscopic examination.

Each tank was assigned a treatment combination (algal diversity: low algal diversity [individual monocultures only] vs. high algal diversity [all 3 monocultures plus the wild collected algae]; trophic structure: fish vs. no fish) in a full factorial design with 3 replicates. Algae were added one day after we began pumping wastewater into tanks (so overflow did not begin until 6 days after algae were added). Chlorella and Scenesdesmus tanks were seeded with $660 \mathrm{~mL}$ of culture (1.124 and $0.697 \mu \mathrm{g}$ chlorophyll $a$ [Chl $a] \mathrm{mL}^{-1}$, respectively) while Spirulina tanks were seeded with $330 \mathrm{~mL}\left(0.846 \mu \mathrm{g} \mathrm{Chl} a \mathrm{~mL}^{-1}\right)$ due to lower algal volume available for use. For the high algal diversity tanks, $580 \mathrm{~mL}$ total volume of algae was seeded which was a mixture of $330 \mathrm{~mL}$ of the field collected mixture of algae plus $100 \mathrm{~mL}$ each of Chlorella and Scenesdesmus and $50 \mathrm{~mL}$ of Spirulina (mix was $0.561 \mu \mathrm{g} \mathrm{Chl} a \mathrm{~mL}^{-1}$ ) that were added to the tanks in four simultaneous additions. Based on Chl $a$ content, the diverse mixture was 2.65 : $1.65: 1.00: 2.39$ of Chlorella : Scenesdesmus : Spirulina : field collected algae. The inoculation rates in terms of Chl $a$ based on full tank volume (achieved 6 days after inoculation) were $0.326,0.202,0.123$, and $0.143 \mu \mathrm{Chl} a \mathrm{~L}^{-1}$ for Chlorella, Scenedesmus, Spirulina, and mix treatments, respectively.

To test whether adding zooplanktivorous fish to open tank reactors will increase algal production by providing top down ecological control of algal grazers, 15 individual mosquito fish (Gambusia affinis) were added into each of the 6 tanks assigned to that treatment. G. affinis (a mix of juveniles and mature males and females) were collected with dip nets from a small tributary of Brays Bayou $\left(29.68625^{\circ} \mathrm{N}, 95.44678^{\circ} \mathrm{W}\right)$ in Houston, transported in aerated buckets to the experimental site $(\sim 15 \mathrm{~km})$, and immediately transferred to the tanks. At the conclusion of the experiment, fish were captured with dip nets, transported in aerated buckets back to the same location where they were originally collected, and immediately released. More than 15 fish were captured and released from each tank indicating that they reproduced during the experiment. Except for visual analysis, no quantitative or qualitative analyses were done on the fish populations. The methods were carried out in accordance with the guidelines approved by the Rice University Institutional Animal Care and Use Committee (IACUC protocol No. A12051501).

\section{Data collection}

Throughout the experiment at intervals of 15 days, we sampled and measured response variables related to water quality and nutrient removal in the water being put into and being drained from tanks (including $\mathrm{N}$ and P) and algal production as total suspended solids (TSS, measured as dry mass). In situ dissolved oxygen, $\mathrm{pH}$, temperature, and total dissolved solids were measured using field meters (Exstik-600K; Extik-PH100; Exstik EC 400; Extech Instruments, Nashua, NH, USA).

A depth integrated water column sample was collected from each reactor for evaluation of dry weight, $\mathrm{Chl} a$, algal community structure, lipids, nitrogen, and phosphorus. Samples were stored in 500-mL acid washed amber glass bottles equipped with teflon lined caps and temporarily placed on ice. In the laboratory, aliquots of samples after 
filtration were separately packed and sent off for analysis at specialized laboratories. Analyses of filtered water (algae removed by filtration) for $\mathrm{N}$ and $\mathrm{P}$ were conducted by the Texas A \& M University Soil, Water and Forage Testing Laboratory. Lipid analysis was conducted by the Center for Electromechanics, University of Texas, Austin using the modified method of Bligh and Dyer (1959). Two aliquots of $50 \mathrm{~mL}$ each from the 12 reactors were filtered through Whatmans GF/F filters and one set was used for chlorophyll extraction and estimation.

\section{Chlorophyll estimation}

Chl $a$ was extracted with $100 \%$ methanol, left overnight in the dark at $4^{\circ} \mathrm{C}$ for full extraction and estimated by measuring the optical density at $663 \mathrm{~nm}$ (MacKinney 1941, Banerjee et al. 2004). The other 50-mL aliquot was used for estimating the dry weight of algae. A dried pre-weighed Whatman GF/C filter paper (pore size 45 $\mu \mathrm{m}$ ) was used and the algae were dried overnight in an incubator at $101^{\circ} \mathrm{C}$. Algal species composition was determined by microscopic examination at regular intervals.

\section{Lipid analysis}

To analyze total lipids each sample was mixed thoroughly and $10 \mathrm{~mL}$ from each sample was pelleted via centrifugation. The pellet was resuspended in $8 \mathrm{~mL}$ of methanol, incubated at $65^{\circ} \mathrm{C}$ for $1 \mathrm{~h}$. Then $4 \mathrm{~mL}$ of chloroform was added and the mixture was incubated at $50^{\circ} \mathrm{C}$ for 1 $\mathrm{h}$. This process was repeated to recover additional lipids. The pooled solvents were transferred to a pre-weighed vial, and the solvents containing extracted lipids were evaporated overnight. The vial was re-weighed to yield a gravimetric weight of total extracted lipids. Extracted lipids were normalized to dry cell weight.

\section{FAME analysis}

To analyze FAME conversion, $10 \mathrm{~mL}$ from each sample was pelleted via centrifugation. The pellet was resuspended in $8 \mathrm{~mL}$ of methanol and $1 \mathrm{~mL}$ of $10 \mathrm{~N} \mathrm{KOH}$, and incubated at $65^{\circ} \mathrm{C}$ for $2 \mathrm{~h}$ with gentle mixing every $30 \mathrm{~min}$. Then $0.5 \mathrm{~mL}$ of $24 \mathrm{~N} \mathrm{H}_{2} \mathrm{SO}_{4}$ was added to each sample, and incubated for another $2 \mathrm{~h}$ with gentle mixing every $30 \mathrm{~min}$. Four $\mathrm{mL}$ of hexane was added to each vial, mixed thoroughly, then phase partitioned via centrifugation. The upper hexane layer containing FAMEs, was transferred to a pre-weighed vial, and then evaporated overnight. The vials containing the recovered FAMEs were re-weighed to determine total FAME content. A >95\% conversion of fatty acids to FAMEs was confirmed via thin layer chromatography. Extracted lipids were normalized to dry cell weight.

\section{Statistical analyses}

We examined the effects of algal cultivation on physical and chemical parameters (temperature, $\mathrm{pH}$, dissolved oxygen [DO], total dissolved solids [TDS], nitrate-N, P) in repeated measures ANOVAs with categorical time variables and a single predictor (supply vs. tank).

Another set of repeated measures ANOVAs was conducted that examined the effects of experimental factors on physical parameters, chemical parameters, algal production, and zooplankton abundance (that colonized naturally). The predictors were diversity (algal monoculture vs. diverse algal assemblage), fish (present or absent), and diversity $\times$ fish. Adjusted means partial difference tests were used to examine differences between treatments on a sampling date for significant treatment by time predictors.

ANOVAs were used to examine the effects of experimental factors on lipids (\% of mass and amount) and FAME (\% of lipids and amount).

Repeated-measures MANOVA was used to examine the effects of experimental treatments on algal community composition. This analysis had six response variables that corresponded to the taxonomic groups found in our censuses. Analyses were conducted using SAS version 9.0 (SAS Institute Inc., Cary, NC, USA).

\section{RESULTS}

\section{Comparisons of tanks and supply water}

The water in tanks differed from the supply water for all physical and chemical characteristics we measured. Compared to supply water, the water in tanks had lower temperatures (tanks, $30.11 \pm 0.03^{\circ} \mathrm{C}$; supply, $32.70 \pm$ $0.12^{\circ} \mathrm{C} ; \mathrm{F}_{1,11}=425.8 ; \mathrm{p}<0.0001$ ) (Fig. 1A), higher $\mathrm{pH}$ (tanks, $7.80 \pm 0.07$; supply, $2.61 \pm 0.23 ; \mathrm{F}_{1,11}=467.2 ; \mathrm{p}<0.0001$ ) (Fig. 1B), higher dissolved oxygen (tanks, $11.25 \pm 0.12 \mathrm{mg}$ $\mathrm{L}^{-1}$; supply, $1.78 \pm 0.41 \mathrm{mg} \mathrm{L}^{-1} ; \mathrm{F}_{1,11}=497.7 ; \mathrm{p}<0.0001$ ) (Fig. 1C), and lower TDS (tanks, $457.85 \pm 3.13 \mathrm{mg} \mathrm{L}^{-1}$; supply, $503.05 \pm 11.40 \mathrm{mg} \mathrm{L}^{-1} ; \mathrm{F}_{1,11}=10.1 ; \mathrm{p}<0.01$ ) (Fig. 1D). All of these parameters also varied significantly with sampling period (temperature: $\mathrm{F}_{12,132}=250.93, \mathrm{p}<0.0001 ; \mathrm{pH}: \mathrm{F}_{12,132}$ $=10.39, \mathrm{p}<0.0001 ;$ DO: $\mathrm{F}_{12,132}=9.11, \mathrm{p}<0.0001 ;$ TDS: $\mathrm{F}_{12,132}$ 

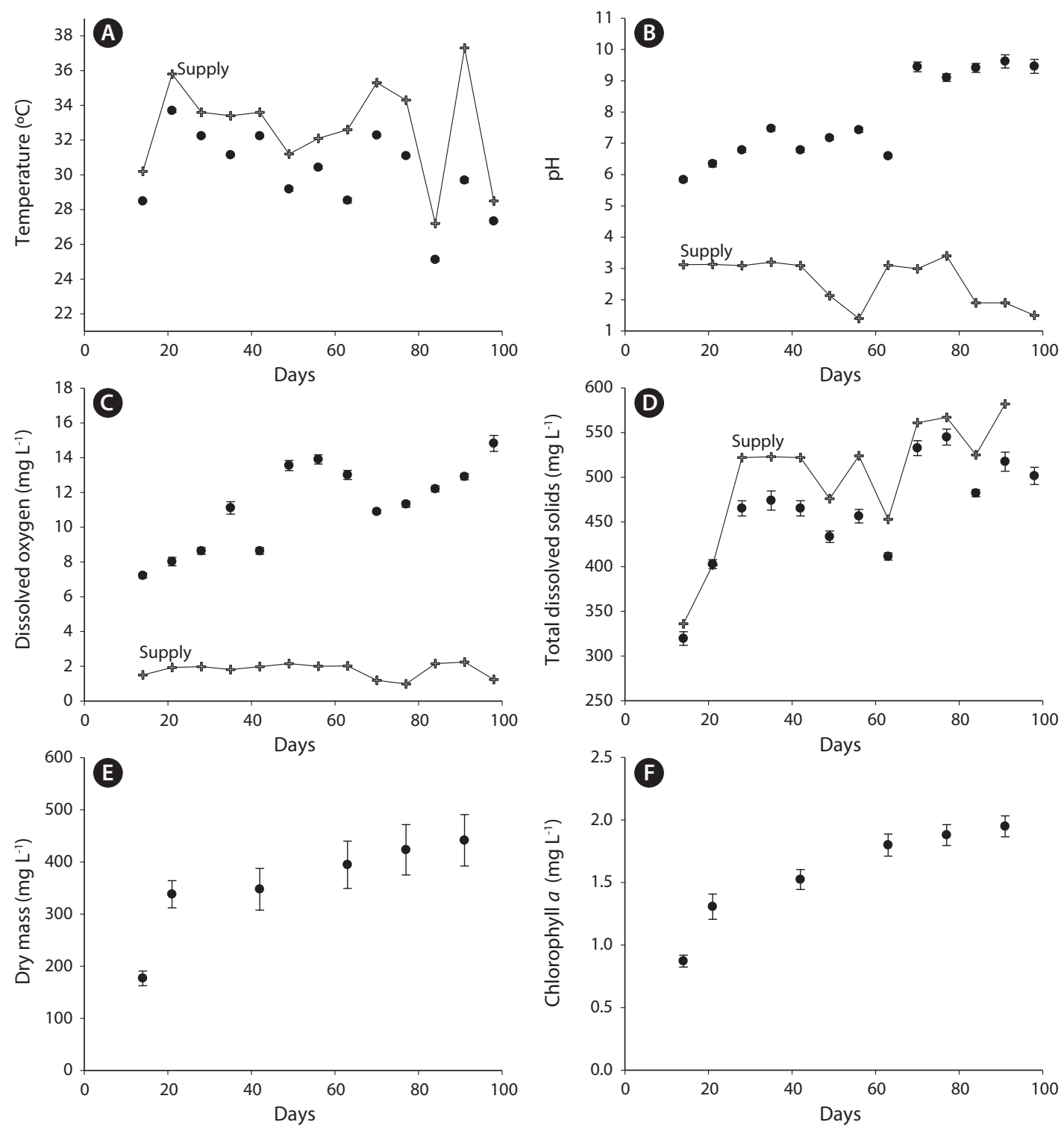

Fig. 1. Effects of algal growth on physical parameters. (A) Temperature. (B) pH. (C) Dissolved oxygen. (D) Total dissolved solids. (E) Mass. (F) Chlorophyll $a$. Values are presented as means \pm standard error. Crosses and black lines indicate supply water. Circles indicate tanks seeded with algae.

$=10.18, \mathrm{p}<0.0001)$ as did the magnitude of the differences between tanks and supply water (i.e., date by tank vs. supply interaction term) for all these parameters except TDS (temperature: $\mathrm{F}_{12,132}=30.03, \mathrm{p}<0.0001 ; \mathrm{pH}: \mathrm{F}_{12,132}=$ 22.38, $\mathrm{p}<0.0001$; DO: $\mathrm{F}_{12,132}=8.74, \mathrm{p}<0.0001$;DS: $\mathrm{F}_{12,132}$ $=0.21, \mathrm{p}=0.997$ )

The supply water had relatively higher concentrations of nitrate- $\mathrm{N}$, lower concentrations of $\mathrm{P}$, and higher $\mathrm{N}$ : $\mathrm{P}$ on day 77 compared to day 91. Compared to supply water, the water in tanks had significantly lower concentrations of nitrate- $\mathrm{N}\left(\mathrm{F}_{1,11}=136.7, \mathrm{p}<0.0001\right)$ and phosphorus $\left(\mathrm{F}_{1,11}=18.8, \mathrm{p}<0.01\right)$. Compared to the supply water, nitrate- $\mathrm{N}$ was reduced by $91 \%$ (supply, $14.74 \pm 1.08 \mathrm{ppm}$; tanks, $1.60 \pm 0.31 \mathrm{ppm}$ ) (Fig. 2A) and phosphorus was reduced by $53 \%$ (supply, $5.10 \pm 0.65$ ppm; tanks, $2.19 \pm 0.19$ ppm) (Fig. 2B). Neither nitrate-N nor P (in terms of the experiment-wide average of supply water and tanks) varied significantly between the two sampling periods (each $\mathrm{p}>$ $0.51)$. The reductions in nitrate- $\mathrm{N}$ and $\mathrm{P}$ from uptake were independent of sampling periods as well (each $\mathrm{p}>0.48$ ).

\section{Comparisons among tanks}

Experimental treatments had few effects on any chem- 

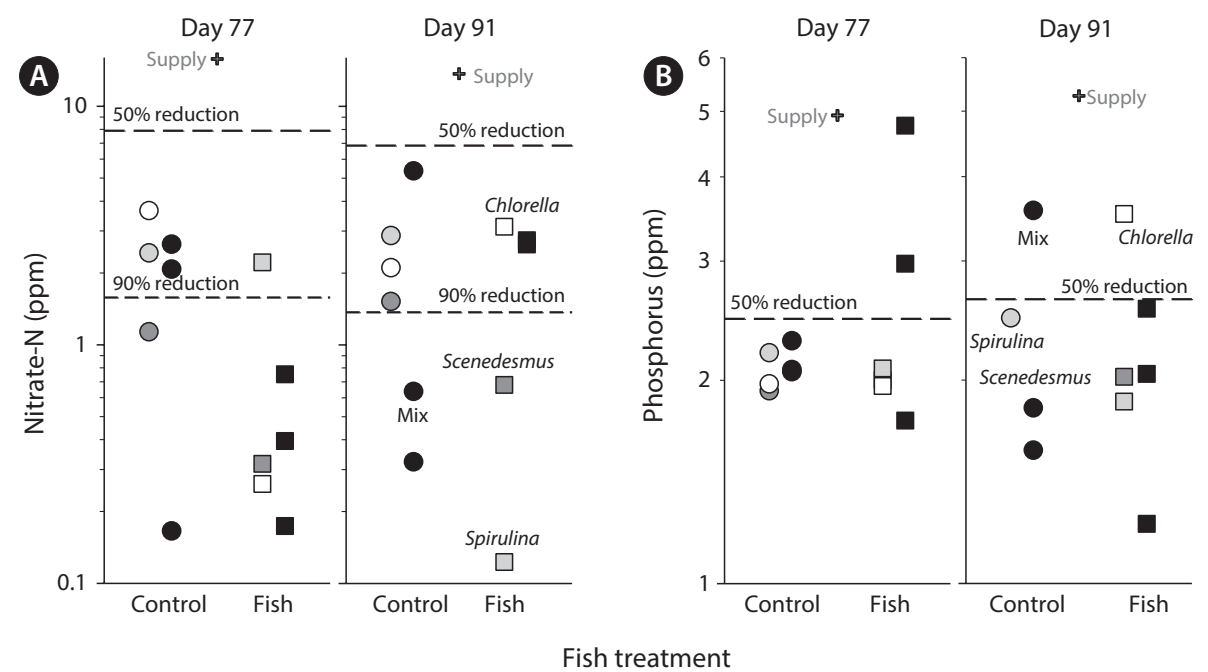

Fig. 2. Nitrate-N (A) and phosphorus (B) in water in experimental tanks with algae compared to supplied wastewater. Each data point represents an individual tank. Crosses indicate supply water. Circles indicate tanks without fish and squares indicate tanks with fish added. Symbol color indicates taxonomic composition of monocultures (white, Chlorella; dark gray, Scenedesmus; gray, Spirulina; black, mixed).


Fish treatment

Fig. 3. Production of mass (A), total lipids (B), and fatty acid methyl esters (FAMEs) (C). Samples are from day 77 . Each data point represents an individual tank. Crosses indicate supply water. Circles indicate tanks without fish and squares indicate tanks with fish added. Symbol color indicates taxonomic composition of monocultures (white, Chlorella; dark gray, Scenedesmus; gray, Spirulina; black, mixed).

ical or physical characteristics. There were no significant effects of treatments alone or in interaction on temperature, $\mathrm{pH}$, TDS, $\mathrm{N}$ or $\mathrm{P}$ (Table 1). DO was significantly higher in tanks seeded with algal monocultures (significant diversity effect) compared to those seeded with mixtures (Table 1). All of these chemical and physical characteristics varied significantly with time but there were no significant interactions of experimental treatments and time (Table 1).

Dry mass (Figs 1E \& 3A) but not Chl $a$ (Fig. 1F) were significantly higher in tanks seeded with algal monocultures compared to tanks seeded with mixtures (Table 1).
Mass in monocultures was significantly higher than that in mixtures starting from day 42 to the end of the experiment. By the first sampling period (day 14), mass was independent of inoculation amounts $(\mathrm{z}=1.68, \mathrm{p}<0.09)$. Lipid concentrations (range, 12.2 to $44.3 \mathrm{mg} \mathrm{L}^{-1}$; average, $25.14 \mathrm{mg} \mathrm{L}^{-1}$ ), lipid content per dry weight (Spirulina 0.061 $\mathrm{g} \mathrm{g}^{-1}$, Chlorella $0.053 \pm 0.0028 \mathrm{~g} \mathrm{~g}^{-1}$, Scenesdesmus $0.061 \pm$ $0.015 \mathrm{~g} \mathrm{~g}^{-1}$, mixture $0.068 \pm 0.044 \mathrm{~g} \mathrm{~g}^{-1}$, average $0.63 \mathrm{~g} \mathrm{~g}^{-1}$, total lipids (Fig. 3B), and FAME concentrations were independent of all experimental treatments (Table 1). FAME content was significantly higher for monocultures (Table 1, Fig. 3C). 


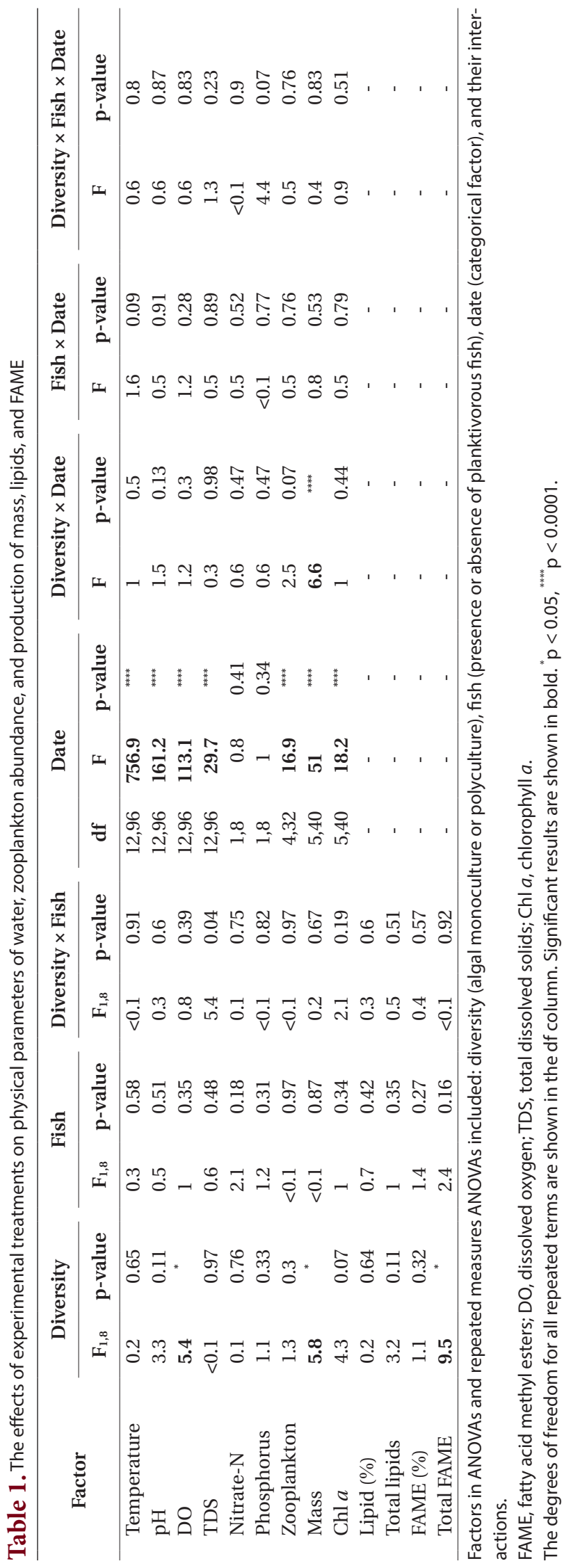

Zooplankton abundance was independent of all treatments (Table 1, Fig. 4). Zooplankton abundance varied significantly with time but there were no significant interactions of time and treatments (Table 1). In the MANOVA, algal genus composition depended significantly on diversity ( $\mathrm{p}<0.0001)$ but not fish $(\mathrm{p}=0.9227)$ or fish $\times$ diversity $(\mathrm{p}=0.8761)$. Algal genus composition varied over time ( $p$ $<0.0001)$ but the effects of treatments did not vary with time (diversity $\times$ date: $\mathrm{p}=0.3547$; fish $\times$ date: $\mathrm{p}=0.6833$; diversity $\times$ fish $\times$ date: $p=0.6801$ ). Contamination with other algal species was not noticed or detected in monoculture tanks other than the ones that were seeded into the tank (Fig. 4).

\section{DISCUSSION}

Contrary to some previous reports we found that our monocultures (Chlorella, Scenedesmus, and Spirulina) were stable both in terms of production and algal taxonomic composition and all were resistant to invasion as apparent from regular microscopic observations that found no other algal taxa present. Even Spirulina, which was a marine form, could grow in wastewater and produce significant biomass. This was not surprising given that cyanobacteria have the great adaptability to variations in environmental factors. Other authors have reported the use of Spirulina grown on Zarrouk's medium in wastewater treatment (Mezzomo et al. 2010, Amala and Ramanathan 2013, Chaiklahan et al. 2013, Ismail et al. 2013). Indeed, monoculture tanks were more productive than the tanks seeded with a diverse assemblage of algae. Based on the analysis of lipid and FAME content, these tanks were also productive in terms of energy rich biomass suitable for biodiesel production. Moreover, rates of nutrient removal were high. The presence of planktivorous fish did not affect productivity, stability, or rates of nutrient removal. Such results have not previously been reported for algae grown in open wastewater fed reactors.

Compared to the other published study of open-tank wastewater fed reactors which was conducted in Kansas, USA (Sturm et al. 2012), our productivity in terms of lipids per liquid volume was, on average, three times higher (25.4 $\mathrm{mg} \mathrm{L}^{-1}$ vs. $8.35 \mathrm{mg} \mathrm{L}^{-1}$ ). Our tanks were much warmer on average than those in Kansas. Our tanks averaged $30.3^{\circ} \mathrm{C}$ while the other study had temperatures of $16.4^{\circ} \mathrm{C}$ during the start-up period and $10.6^{\circ} \mathrm{C}$ during the stable operation period. If the higher temperature of our tanks is related to higher productivity, this suggests that warm locations such as Houston might be especially suitable for 



Fig. 4. Algal species composition over the course of the experiment. For monocultures, each data point represents an individual tank without (A, C \& E) or with fish added (B, D \& F). For tanks that received a diverse mixture of algae, each data point is the average of three tanks without (G) or with fish added $(\mathrm{H})$. Circles indicate strains included in monocultures (white, Chlorella; dark gray, Scenedesmus; gray, Spirulina), black triangles indicate zooplankton, and diamonds indicate algae not included in monocultures (dark gray, Aphanocapsa [cyanobacteria]; white, Chlamydomonas [Chlorophyta]; gray, Euglena [Euglenoids]; light gray, diatoms [Dinophyta]). 
such an industry. In comparison, our supplied wastewater was lower in nitrogen (14.7 $\mathrm{mg} \mathrm{L}^{-1}$ vs. $\left.20.4 \mathrm{mg} \mathrm{L}^{-1}\right)$, higher in phosphorus ( $5.1 \mathrm{mg} \mathrm{L}^{-1}$ vs. $3.5 \mathrm{mg} \mathrm{L}^{-1}$ ), and had a lower mass ratio of $\mathrm{N}$ to $\mathrm{P}(2.9$ vs. 5.8). It is possible that these differences in nutrients also played a role in differences in productivity. However, $\mathrm{pH}$ and DO were similar and so differences in those factors are not likely responsible for differences in productivity. There also may have been less shading due to biomass accumulation because our tanks were half as deep. In this experiment, lab-grown selected algal strains were used to inoculate our tanks, along with wild isolates in the mix treatments, while the study in Kansas only used wild isolates. The use of cultured algae is important compared to wild isolates when one considers commercialization of the bioremediation process and biomass generation for biodiesel production. There were also differences in experimental methodology such as inoculation rates, timing of inoculation vs. filling, and days to first overflow after inoculation. Because the differences in productivity (and fish effects, see below) were large, understanding the causes of variation is important. The potential roles of different changes in water chemistry on algae, zooplankton, and fish on the results we found here cannot be disentangled without additional experimental factors.

Total lipid and FAME analysis showed high lipid production in the algal biomass of all treatments. Estimates of FAME predicted that almost $80 \%$ of the lipids could be converted into biodiesel (Fig. 3). The total FAME data obtained in this study is comparable to that obtained by Ramachandra et al. (2013) although the algal species and conditions were different then what we used. Lipid productivity (mass of lipid that can be produced per day) is dependent on the lipid content of the algal biomass. Algal biodiesel production will therefore be limited by the standing crop of the microalgae and also by the lipid content. Both the quality and quantity of lipids produced will vary with the identity of the algal species as well as the site specific growth conditions (Brennan and Owende 2010, Sydney et al. 2011, Yang et al. 2011, Stockenreiter et al. 2012). This variability probably reflects alteration in relative rates of production and utilization of storage lipids and modifications in the properties of cellular membranes (Rodolfi et al. 2009). Our lipid and FAME estimation results clearly show that it has high probability of converting to significant amounts of biodiesel. This is all the more probable as we have used algal species selected for high lipid content. Optimizing stress conditions to obtain the highest possible lipid yields in the cells may also be important. Nitrogen starvation has been shown to increase total lipid content in many algal species (Pulz and Gross 2004, García et al. 2006, Elser et al. 2007). In addition, nitrogen availability is a major factor determining the algal lipid class composition (Tedesco and Duerr 1989, Gordillo et al. 1998, Alonso et al. 2000). The high rates of nitrogen removal and low nutrient concentrations in discharge water suggest that either nitrogen or phosphorus could have been limiting nutrients in this study and suggest that it may be possible to obtain higher or lower lipid content depending on the nitrogen and phosphorus content of wastewater (Smith et al. 2010). It is possible that sampling at a finer temporal resolution might have provided more power to examine effects of treatments.

The low concentrations of available nutrients in tanks may also be responsible for the stable monocultures that were apparently resistant to invasion by other types of algae. If monocultures inoculated in the wastewater fed open bioreactors took up available nutrients at a very fast rate creating a nutrient deficient environment, it is possible that this may have prevented the establishment of contaminating species in our tanks (Shurin et al. 2013). The inoculation rates here were low (about $1: 10,000$ of the Chl $a$ measured on day 14) which indicates that growth rates after inoculation must have been rapid with populations doubling in less than a day. Another study found that Chlorella had a doubling time of $8.6 \mathrm{~h}$ at $27^{\circ} \mathrm{C}$ and a doubling time of $48.5 \mathrm{~h}$ at $5^{\circ} \mathrm{C}$ (Maxwell et al. 1994). This suggests that the warm temperatures in tanks may have played a role in the rapid growth and high rates of nutrient uptake that may be related to their taxonomic stability.

The amounts of nutrients in water discharged from the tanks (after algal removal) were much lower than those in supplied wastewater. Indeed, algae cultivation removed more than $90 \%$ of the nitrogen and more than half of the phosphorus from supplied wastewater (Fig. 2). In comparison to the study in Kansas, the removal of nitrogen was much higher (91\% vs. $19 \%$ ) but the removal of phosphorus was only slightly higher ( $57 \%$ vs. $46 \%$ ) (Sturm et al. 2012). In terms of concentrations in the discharge water after algal removal, in this study the concentrations of nitrogen were much lower $\left(2.3 \mathrm{mg} \mathrm{L}^{-1}\right.$ vs. $\left.16.5 \mathrm{mg} \mathrm{L}^{-1}\right)$ while phosphorus concentrations were comparable $(2.0$ $\mathrm{mg} \mathrm{L}^{-1}$ vs. $\left.1.9 \mathrm{mg} \mathrm{L}^{-1}\right)$. Overall, the high rates of nutrient removal found here were consistent with high algal production perhaps in combination with a similar minimum available phosphorus concentration. The results (Fig. 2) showed variation in rates of nutrient removal but this variation did not depend on treatments. 
There was no positive effect of algal diversity on any variable which is consistent with stable, highly productive monocultures. Algal researchers typically prefer monoculture production and go to considerable lengths to maintain the purity of their cultures but it has been suggested that monocultures will not be stable or productive in open tank systems (Smith et al. 2010). The higher productivity of monocultures than diverse mixtures that include those species ("underyielding") is not predicted by well-accepted models of diversity and productivity (Loreau et al. 2001). Diversity is known to affect productivity either through sampling effects in which diverse communities are more likely to include the most productive species or niche differentiation and complementarities in resource utilization (Shurin et al. 2013). The sampling effect leads to polycultures equivalent to the most productive monocultures and niche complementarities leads to polycultures more productive than every monoculture ("overyielding"). One mechanism that can lead to underyielding is direct negative interactions among algal species. In fact, allelopathic interactions are an important factor in determining species presence and abundance within planktonic communities. Microalgal allelopathy in certain groups of algae like the diatoms and cyanobacteria may negatively affect the performance of each other while existing as a mixed community in the same environment (Bacellar Mendes and Vermelho 2013). This is consistent with our study in which Chlorella has the highest growth rate as a monoculture but not when present as a part of the mixed culture which has members of the diatoms and cyanobacteria (Fig. 4). The amounts of algal mass (estimated as $\mathrm{Chl} a$ ) added at the start of the experiment varied but all were many orders of magnitude less than the mass found at the first sampling event and mass at that first sampling event was independent of inoculation rates. Of course, it is possible that positive effects of diversity on productivity, nutrient removal, and stability might have occurred in a longer experiment.

In contrast to the Kansas study in which the presence of fish significantly increased $\mathrm{Chl} a$ concentrations, TSS, and greater lipid production (Sturm et al. 2012), no effect of fish on Chl $a$ concentrations, mass, lipids or FAME amounts were found (Table 1, Fig. 3). This is consistent with the lack of an effect of fish on zooplankton abundance (Table 1, Fig 4). The effects of top down interactions in fresh waters can be modified by many factors including the absolute nutrient content of the water and morphometry of the system (Jeppesen et al. 2003). Also because outdoor photobioreactors exhibit even more strongly compressed aquatic food webs than most natu- ral lakes, they are extremely sensitive to dynamic instabilities (McCann et al. 2005). Perhaps the lack of a fish effect in our study reflected the fact that the tanks were quickly colonized by aquatic insects such as Libellulidae (Odonata, dragonfly nymphs) and Notonectidae (Hemiptera, backswimmers) that could of provide top-down control of zooplankton independent of fish. Numerous dragonfly larvae could be observed in all tanks throughout the experiment, exuviae were observed on sides of tanks, and dozens of larvae were present in each tank when the experiment ended. Because young dragonfly larvae and backswimmers are voracious predators of zooplankton, including cladocerans such as Daphnia (Burks et al. 2001) that are thought to have large effects on standing crops of phytoplankton (Cottenie et al. 2001), there may have been strong top-down control of zooplankton and high algal standing crops even in the absence of fish. Dragonfly populations are affected by many factors that vary at local (vegetation, water quality) to regional (temperature) spatial scales (Lasswell and Mitchell 1997) so even if high dragonfly abundances contributed to top-down regulation of zooplankton in the absence of fish, it is not clear what allowed those high abundances in this study. In addition, without having done gut analyses of fish in this study, we cannot be sure that they consumed zooplankton in these tanks though this seems likely given that they are a generalist zooplankton feeder (Gophen et al. 1998, Mansfield and McArdle 1998). Finally, because all of the tanks in this experiment were colonized by zooplankton, we do not know what effects the fish would have had on algal production in the absence of zooplankton.

The results of this pilot experiment are not equivalent to establishing long-term, large-scale, commercial efforts. However, they add to the set of demonstrations that algal biomass can be grown in open tank bioreactors using wastewater as a nutrient source for biodiesel production. Perhaps the most interesting aspect of this study was the successful cultivation of stable and highly productive monocultures in open tanks which challenges the idea that wastewater-fed open pond systems will quickly become contaminated and therefore are not suitable for commercial production systems. Rates of nutrient removal, especially nitrogen, from wastewater were also much higher then what has been previously reported. The marked differences between this study and others motivate additional studies to examine the factors which underlie these large differences in productivity and nutrient removal including variation in wastewater chemistry, temperature, and naturally recruiting predators of zooplankton. 


\section{ACKNOWLEDGEMENTS}

We would like to thank Antonella Georgescu, Nakia Hillsman, Jason Iken, Carol LaBreche, Sarah Mason, Walid Samarneh, and Val Smith for helpful discussions; Juli Carrillo, Dylan Siemann, and Candice Tiu for their help in the field; two reviewers for helpful comments; and the City of Houston for permission to conduct the experiment and access to the WWTP.

\section{REFERENCES}

Ahrens, T. \& Sander, H. 2010. Microalgae in waste water treatment: green gold from sludge? Bioforum Eur. 14:16-18.

Alonso, D. L., Belarbi, E.-H., Fernández-Sevilla, J. M., Rodríguez-Ruiz, J. \& Grima, E. M. 2000. Acyl lipid composition variation related to culture age and nitrogen concentration in continuous culture of the microalga Phaeodactylum tricornutum. Phytochemistry 54:461-471.

Amala, K. \& Ramanathan, N. 2013. Comparative studies on production of Spirulina platensis on the standard and newly formulated alternative medium. Sci. Park 1:1-10.

Bacellar Mendes, L. B. \& Vermelho, A. B. 2013. Allelopathy as a potential strategy to improve microalgae cultivation. Biotechnol. Biofuels 6:152.

Banerjee, M. \& John, J. 2005. Phosphatase activity of nonhair forming cyanobacterium Rivularia and its role in phosphorus dynamics in deepwater rice-fields. Appl. Ecol. Environ. Res. 3:55-60.

Banerjee, M. \& Kushwaha, D. S. 2005. In situ studies on algae from Shahpura Lake: nitrate metabolism and its contribution to nitrogen economy. Ecol. Environ. Conserv. 11:363-366

Banerjee, M., Mishra, S. \& Chatterjee, J. 2004. Scavenging of nickel and chromium toxicity in Aulosira fertilissima by immobilization: effect on nitrogen assimilating enzymes. Electron. J. Biotechnol. 7:302-309.

Banerjee, M. \& Yadav, S. G. 2009. Cyanobacterial mitigation and lead toxicity. J. Plant Sci. Res. 25:231-235.

Batan, L., Quinn, J., Willson, B. \& Bradley, T. 2010. Net energy and greenhouse gas emission evaluation of biodiesel derived from microalgae. Environ. Sci. Technol. 44:79757980.

Bligh, E. G. \& Dyer, W. J. 1959. A rapid method of total lipid extraction and purification. Can. J. Biochem. Physiol. 37:911-917.

Borowitzka, M. A. 1995. Microalgae as sources of pharmaceuticals and other biologically active compounds. J. Appl. Phycol. 7:3-15.
Brennan, L. \& Owende, P. 2010. Biofuels from microalgae: a review of technologies for production, processing, and extractions of biofuels and co-products. Renew. Sustain. Energy Rev. 14:557-577.

Bruton, T., Lyons, H., Lerat, Y., Stanley, M. \& Rasmussen, M. B. 2009. A review of the potential of marine algae as a source of biofuel in Ireland. Sustainable Energy Ireland, Dublin, $88 \mathrm{pp}$.

Burks, R. L., Jeppesen, E. \& Lodge, D. M. 2001. Pelagic prey and benthic predators: impact of odonate predation on Daphnia. J. N. Am. Benthol. Soc. 20:615-628.

Carpenter, S. R., Christensen, D. L., Cole, J. J., Cottingham, K. L., He, X., Hodgson, J. R., Kitchell, J. F., Knight, S. E., Pace, M. L., Post, D. M. \& Voichick, N. 1995. Biological control of eutrophication in lakes. Environ. Sci. Technol. 29:784-786.

Carpenter, S. R., Kitchell, J. F. \& Hodgson, J. R. 1985. Cascading trophic interactions and lake productivity. Bioscience 35:634-639.

Chaiklahan, R., Chirasuwan, N., Siangdung, W., Paithoonrangsarid, K. \& Bunnag, B. 2013. Cultivation of Spirulina platensis using pig wastewater in a semi-continuous process. J. Microbiol. Biotechnol. 20:609-614.

Chisti, Y. \& Yan, J. 2011. Energy from algae: current status and future trends algal biofuels: a status report. Appl. Energy 88:3277-3279.

Clarens, A. F., Resurreccion, E. P., White, M. A. \& Colosi, L. M. 2010. Environmental life cycle comparison of algae to other bioenergy feedstocks. Environ. Sci. Technol. 44:1813-1819.

Cottenie, K., Nuytten, N., Michels, E. \& De Meester, L. 2001. Zooplankton community structure and environmental conditions in a set of interconnected ponds. Hydrobiologia 442:339-350.

Craggs, R. J., Heubeck, S., Lundquist, T. J. \& Benemann, J. R. 2011. Algal biofuels from wastewater treatment high rate algal ponds. Water Sci. Technol. 63:660-665.

Dalrymple, O. K., Halfhide, T., Udom, I., Gilles, B., Wolan, J., Zhang, Q. \& Ergas, S. 2013. Wastewater use in algae production for generation of renewable resources: a review and preliminary results. Aquat. Biosyst. 9:2.

Elser, J. J., Bracken, M. E. S., Cleland, E. E., Gruner, D. S., Harpole, W. S., Hillebrand, H., Ngai, J. T., Seabloom, E. W., Shurin, J. B. \& Smith, J. E. 2007. Global analysis of nitrogen and phosphorus limitation of primary producers in freshwater, marine and terrestrial ecosystems. Ecol. Lett. 10:1135-1142.

Fortier, M. -O. P. \& Sturm, B. S. M. 2012. Geographic analysis of the feasibility of collocating algal biomass production with wastewater treatment plants. Environ. Sci. Technol. 
46:11426-11434.

García, J., Green, B. F., Lundquist, T., Mujeriego, R., Hernández-Mariné, M. \& Oswald, W. J. 2006. Long term diurnal variations in contaminant removal in high rate ponds treating urban wastewater. Bioresour. Technol. 97:17091715.

Gophen, M., Yehuda, Y., Malinkov, A. \& Degani, G. 1998. Food composition of the fish community in Lake Agmon. Hydrobiologia 380:49-57.

Gordillo, F. J. L., Goutx, M., Figueroa, F. L. \& Niell, F. X. 1998. Effects of light intensity, $\mathrm{CO}_{2}$ and nitrogen supply on lipid class composition of Dunaliella viridis. J. Appl. Phycol. 10:135-144.

Huntley, M. E. \& Redalje, D. G. 2007. $\mathrm{CO}_{2}$ mitigation and renewable oil from photosynthetic microbes: a new appraisal. Mitig. Adapt. Strateg. Glob. Change 12:573-608.

Ismail, H., Abd El-All, A. A. M. \& Hassanein, H. A. M. 2013. Biological influence of some microorganisms on olive mill wastewater. Egypt. J. Agric. Res. 91:1-9.

Jeppesen, E., Jensen, J. P., Jensen, C., Faafeng, B., Hessen, D. O., Søndergaard, M., Lauridsen, T., Brettum, P. \& Christoffersen, K. 2003. The impact of nutrient state and lake depth on top-down control in the pelagic zone of lakes: a study of 466 lakes from the temperate zone to the Arctic. Ecosystems 6:313-325.

Lam, M. K. \& Lee, K. T. 2012. Microalgae biofuels: a critical review of issues, problems and the way forward. Biotechnol. Adv. 30:673-690.

Lardon, L., Hélias, A., Sialve, B., Steyer, J. -P. \& Bernard, O. 2009. Life-cycle assessment of biodiesel production from microalgae. Environ. Sci. Technol. 43:6475-6481.

Lasswell, J. L. \& Mitchell, F. L. 1997. Survey of dragonflies (Odonata: Anisoptera) in ponds of Central Texas. J. Kans. Entomol. Soc. 70:52-63.

Laws, E. A., Taguchi, S., Hirata, J. \& Pang, L. 1988. Optimization of microalgal production in a shallow outdoor flume. Biotechnol. Bioeng. 32:140-147.

Loreau, M., Naeem, S., Inchausti, P., Bengtsson, J., Grime, J. P., Hector, A., Hooper, D. U., Huston, M. A., Raffaelli, D., Schmid, B., Tilman, D. \& Wardle, D. A. 2001. Biodiversity and ecosystem functioning: current knowledge and future challenges. Science 294:804-808.

MacKinney, G. 1941. Absorption of light by chlorophyll solutions. J. Biol. Chem. 140:315-322.

Mansfield, S. \& McArdle, B. H. 1998. Dietary composition of Gambusia affinis (Family Poeciliidae) populations in the northern Waikato region of New Zealand. N. Z. J. Mar. Freshw. Res. 32:375-383.

Maxwell, D. P., Falk, S., Trick, C. G. \& Huner, N. P. A. 1994. Growth at low temperature mimics high-light acclima- tion in Chlorella vulgaris. Plant Physiol. 105:535-543.

McCann, K. S. 2000. The diversity-stability debate. Nature 405:228-233.

McCann, K. S., Rasmussen, J. B. \& Umbanhowar, J. 2005. The dynamics of spatially coupled food webs. Ecol. Lett. 8:513-523.

Mezzomo, N., Saggiorato, A. G., Siebert, R., Tatsch, P. O., Lago, M. C., Hemkemeier, M., Costa, J. A. V., Bertolin, T. E. \& Colla, L. M. 2010. Cultivation of microalgae Spirulina platensis (Arthrospira platensis) from biological treatment of swine wastewater. Ciênc. Tecnol. Aliment 30:173-178.

Odlare, M., Nehrenheim, E., Ribé, V., Thorin, E., Gavare, M. \& Grube, M. 2011. Cultivation of algae with indigenous species: potentials for regional biofuel production. Appl. Energy 88:3280-3285.

Olaizola, M. 2003. Commercial development of microalgal biotechnology: from the test tube to the marketplace. Biomol. Eng. 20:459-466.

Park, J. B. K., Craggs, R. J. \& Shilton, A. N. 2011. Wastewater treatment high rate algal ponds for biofuel production. Bioresour. Technol. 102:35-42.

Pittman, J. K., Dean, A. P. \& Osundeko, O. 2011. The potential of sustainable algal biofuel production using wastewater resources. Bioresour. Technol. 102:17-25.

Pulz, O. \& Gross, W. 2004. Valuable products from biotechnology of microalgae. Appl. Microbiol. Biotechnol. 65:635-648.

Ramachandra, T. V., Madhab, M. D., Shilpi, S. \& Joshi, N. V. 2013. Algal biofuel from urban wastewater in India: scope and challenges. Renew. Sustain. Energy Rev. 21:767-777.

Rawat, I., Kumar, R. R., Mutanda, T. \& Bux, F. 2011. Dual role of microalgae: phycoremediation of domestic wastewater and biomass production for sustainable biofuels production. Appl. Energy 88:3411-3424.

Rizzi, F., van Eck, N. J. \& Frey, M. 2014. The production of scientific knowledge on renewable energies: worldwide trends, dynamics and challenges and implications for management. Renew. Energy 62:657-671.

Rodolfi, L., Zittelli, G. C., Bassi, N., Padovani, G., Biondi, N., Bonini, G. \& Tredici, M. R. 2009. Microalgae for oil: strain selection, induction of lipid synthesis and outdoor mass cultivation in a low-cost photobioreactor. Biotechnol. Bioeng. 102:100-112.

Rooney, N. \& McCann, K. S. 2012. Integrating food web diversity, structure and stability. Trends Ecol. Evol. 27:40-46.

Shurin, J. B., Abbott, R. L., Deal, M. S., Kwan, G. T., Litchman, E., McBride, R. C., Mandal, S. \& Smith, V. H. 2013. Industrial-strength ecology: trade-offs and opportunities in 
algal biofuel production. Ecol. Lett. 16:1393-1404.

Smith, V. H., Sturm, B. S. M., deNoyelles, F. J. \& Billings, S. A. 2010. The ecology of algal biodiesel production. Trends Ecol. Evol. 25:301-309.

Stephenson, A. L., Kazamia, E., Dennis, J. S., Howe, C. J., Scott, S. A. \& Smith, A. G. 2010. Life-cycle assessment of potential algal biodiesel production in the United Kingdom: a comparison of raceways and air-lift tubular bioreactors. Energy Fuels 24:4062-4077.

Stockenreiter, M., Graber, A. -K., Haupt, F. \& Stibor, H. 2012. The effect of species diversity on lipid production by micro-algal communities. J. Appl. Phycol. 24:45-54.

Sturm, B. S. M. \& Lamer, S. L. 2011. An energy evaluation of coupling nutrient removal from wastewater with algal biomass production. Appl. Energy 88:3499-3506.

Sturm, B. S. M., Peltier, E., Smith, V. \& deNoyelles, F. 2012. Controls of microalgal biomass and lipid production in municipal wastewater-fed bioreactors. Environ. Prog.
Sustain. Energy 31:10-16.

Sydney, E. B., da Silva, T. E., Tokarski, A., Novak, A. C., de Carvalho, J. C., Woiciecohwski, A. L., Larroche, C. \& Soccol, C. R. 2011. Screening of microalgae with potential for biodiesel production and nutrient removal from treated domestic sewage. Appl. Energy 88:3291-3294.

Tedesco, M. A. \& Duerr, E. O. 1989. Light, temperature and nitrogen starvation effects on the total lipid and fatty acid content and composition of Spirulina platensis UTEX 1928. J. Appl. Phycol. 1:201-209.

Walsh, C. J., Roy, A. H., Feminella, J. W., Cottingham, P. D., Groffman, P. M. \& Morgan, R. P. 2nd. 2005. The urban stream syndrome: current knowledge and the search for a cure. J. N. Am. Benthol. Soc. 24:706-723.

Yang, J., Li, X., Hu, H., Zhang, X., Yu, Y. \& Chen, Y. 2011. Growth and lipid accumulation properties of a freshwater microalga, Chlorella ellipsoidea $\mathrm{YJ} 1$, in domestic secondary effluents. Appl. Energy 88:3295-3299. 